\title{
Promoting universal financial protection: health insurance for the poor in Georgia - a case study
}

\author{
Akaki Zoidze*, Natia Rukhazde, Ketevan Chkhatarashvili and George Gotsadze
}

\begin{abstract}
Background: The present study focuses on the program "Medical Insurance for the Poor (MIP)" in Georgia. Under this program, the government purchased coverage from private insurance companies for vulnerable households identified through a means testing system, targeting up to $23 \%$ of the total population. The benefit package included outpatient and inpatient services with no co-payments, but had only limited outpatient drug benefits. This paper presents the results of the study on the impact of MIP on access to health services and financial protection of the MIP-targeted and general population.

Methods: With a holistic case study design, the study employed a range of quantitative and qualitative methods. The methods included document review and secondary analysis of the data obtained through the nationwide household health expenditure and utilisation surveys 2007-2010 using the difference-in-differences method.
\end{abstract}

Results: The study findings showed that MIP had a positive impact in terms of reduced expenditure for inpatient services and total household health care costs, and there was a higher probability of receiving free outpatient benefits among the MIP-insured. However, MIP insurance had almost no effect on health services utilisation and the households' expenditure on outpatient drugs, including for those with MIP insurance, due to limited drug benefits in the package and a low claims ratio. In summary, the extended MIP coverage and increased financial access provided by the program, most likely due to the exclusion of outpatient drug coverage from the benefit package and possibly due to improper utilisation management by private insurance companies, were not able to reverse adverse effects of economic slow-down and escalating health expenditure. MIP has only cushioned the negative impact for the poorest by decreasing the poor/rich gradient in the rates of catastrophic health expenditure.

Conclusions: The recent governmental decision on major expansion of MIP coverage and inclusion of additional drug benefit will most likely significantly enhance the overall MIP impact and its potential as a viable policy instrument for achieving universal coverage. The Georgian experience presented in this paper may be useful for other low- and middle-income countries that are contemplating ways to ensure universal coverage for their populations.

Keywords: Catastrophic expenditure, Financial protection, Health insurance for the poor, Service utilisation, Targeting the poor, Universal coverage

\section{Background}

Georgia has chosen its own path in reforming the health financing system by allocating general government revenues to purchase relatively comprehensive coverage for the poor identified through the means testing system. The focus on priority groups and specifically on the poor segments of the population is a common feature of health financing reforms in other low- and middle-income countries (LMICs) [1-7]. Nonetheless, the Georgian experience

\footnotetext{
*Correspondence: k.zoidze@curatio.com

Curatio International Foundation, P.O. Box 110, Tbilisi 380079, Georgia
}

can be unique for two reasons. Firstly, the Georgian government has chosen to provide more generous benefits to the poor than to other groups of the population. This is not a common practice globally, as in most cases, the wider welfare entitlements - including those in health are directed towards the most organized or the politically most powerful [8], and the people least likely to be covered are those with high health care requirements and needing financial protection [9]. Secondly, the coverage for the poor is purchased through competing private insurance companies. Only 11 out of 154 LMICs channel at 
least $10 \%$ of their total health expenditure through private risk prepayment schemes and for most of these countries private for-profit schemes are generally limited to the wealthy minority [10]. Columbia and India are the only other LMICs described in the literature that have established a similar Public Private Partnership (PPP) for the insurance of the poor $[11,12]$.

In general, due to reduced bureaucratic process and often better business practices, private health insurance may be more efficient than public or quasi-public social insurance schemes, although the efficiency gains may be outweighed by higher administrative and acquisition costs $[13,14]$. Most of the countries relying on voluntary health insurance are commonly unable to extend coverage to the majority of the population, or tend to leave large segments of the population uncovered (e.g., South Africa, Jordan, Lebanon, Zimbabwe, India) [10]. Fragmentation of the national pools is another problem in countries where mandatory coverage is provided through competing private health insurance companies. These countries (Switzerland, Netherlands and Czech Republic) are compelled to use cross-subsidization between multiple pools to improve equity and viability of the health financing system [15].

There is a consensus that public financing of health care services for the population and particularly for the poor tends to be more equitable and can provide better financial protection $[15,16]$. However, global evidence is inconclusive on the advantages or disadvantages of using private for-profit insurance companies as financial intermediaries in the provision of health insurance for the population and its poorest segments through public funds $[13,17]$. Moreover, there is a near absence of comprehensive reviews of such experiences in LMICs [18]. These factors and emerging challenges in the design and implementation of Georgia's health financing reform targeting the poor [19] inspired a systematic study of the Georgian experience in implementing the large-scale prepayment schemes through a public-private partnership.

By 2006, the government developed a proxy-meanstested system for the detection of poor households. The test includes over 100 variables to estimate a household's welfare standing. All Georgian households are entitled to apply to be included in the poverty database managed by the Social Services Agency (SSA). The households found ineligible for the social assistance can reapply after one year for a repeat eligibility assessment. SSA also conducts regular reviews (at least once in every five years) of the eligibility status of each household receiving the social assistance. The system allows identification of the poor with a sufficient degree of certainty [20,21]. This targeting system was used for the delivery of medical insurance for the poor (MIP) benefits to the poor when the MIP program was launched in 2007-2008. Beneficiaries of MIP are chosen based on welfare scores derived from a proxy means test. Households registered with the SSA database with scores below 70,001 are eligible for MIP. The MIP benefit package covers the following: i) urgent outpatient and inpatient treatment, including necessary diagnostic-laboratory tests to determine the need for hospitalization; ii) planned inpatient services, with an annual insurance limit of 15,000 GEL (1 GEL 0.6 US\$), excluding expenses for cosmetic treatment, aesthetic surgery, resort treatment, sexual disorders, infertility, treatment abroad, sexually transmitted infections, HIV, and hepatitis C; iii) chemotherapy and radiation therapy within 12,000 GEL annual insurance limit; iv) outpatient visits and limited diagnostic and laboratory tests prescribed by the family physician or general practitioner; v) compensation for delivery costs (up to 400 GEL); vi) outpatient prescription drugs from a predefined essential drugs list and with an annual limit of 50 GEL and with $50 \%$ co-payment.

\section{Institutional and purchasing arrangements}

Initially implemented through a public single payer in September 2007, the government contracted out the delivery of MIP benefits to Private Insurance Companies (PICs). This move was most likely triggered by the Post Rose Revolution emphasis by the Georgian leadership on libertarian ideals and "small government" as a main tool in fighting corruption [22]. All 14 PICs operating in Georgia by the year 2007 had the right to participate. The insurance companies contracted health services from a network of predominantly private providers, or provided these through their own clinics and hospitals. Important changes were introduced in mid-2010. The country was divided into 26 medical regions and threeyear contracts for each region were awarded to PICs identified through the competitive tendering procedure. Because of the tendering procedure, the annual insurance premiums were brought down from 180 GEL in 2009 to 116-132 GEL (depending on the region). Since then, MIP voucher holders are obliged to enter into insurance contracts with PICs according to their place of residence. However, beneficiaries have the right to change the insurance carrier once a year, in case they are not satisfied with the services provided. As an important addition, the PICs that won tenders for MIP implementation were mandated to construct/upgrade hospitals and medical centres in respective medical regions to ensure access to quality health services for the MIP beneficiaries insured by them.

While the concrete policy objectives for MIP were never formulated explicitly in any legal or policy document at the initial stage, two main objectives were implied: i) "creation of a targeting system for public financing of health services for the socially vulnerable" and ii) "redirection of the public funds to support the development of private insurance" [23]. Three explicit 
objectives and targets for MIP were defined only after three years of implementation in 2011: i) to increase financial access to health services for the targeted groups of the population; ii) to mitigate the financial burden induced by the health expenditure for the targeted groups of the population; iii) to reduce the out-of-pocket (OOP) expenditure in the health sector. Respectively, three targets and indicators for the year 2012 were determined: i) number of insured under MIP to reach $1,700,000$; ii) reduction of the share of OOPs in total health expenditure by $10 \%$; iii) increased utilisation of outpatient and inpatient services by $2-3 \%$ for the population insured under MIP in 2010 [24].

One of the key objectives of this case study was to assess the impact of these new health financing reform initiatives of the Georgian government. In line with the implicit and explicit MIP objectives described above, the MIP impact was assessed in terms of equity of access to essential health care services and financial protection against the health care costs - which, together, are two key dimensions of the universal coverage plans.
This paper reflects key results and conclusions of the case study, drawing on two years of in-country research (from October 2010 through November 2012). The paper first provides a brief description of the analytical framework and methods used in the study. It then reviews the study results on MIP impact and discusses in more detail the factors that may explain the patterns of the observed impact. MIP impact in this paper is assessed across two dimensions: i) breadth, scope and depth of the achieved coverage for the general population [25] and ii) access to health services and financial protection for the MIPtargeted and general population. Selected economic, social, demographic and health indicators for the country are presented in Table 1.

\section{Methods}

The overall approach used for the presented research was an exploratory and partially explanatory, holistic single case study design.

A variety of qualitative and quantitative research methods, including in-depth interviews with key informants, focus

Table 1 Selected economic, social and health indicators for Georgia for the years 1990, 1993, 2000 and 2003-2010

\begin{tabular}{|c|c|c|c|c|c|c|c|c|c|c|c|}
\hline & 1990 & 1993 & 2000 & 2003 & 2004 & 2005 & 2006 & 2007 & 2008 & 2009 & 2010 \\
\hline \multicolumn{12}{|l|}{ Economic Indicators } \\
\hline GDP per capita (PPP\$) & 4,433 & 1,437 & 2,218 & 2,951 & 3,220 & 3,611 & 4,044 & 4,687 & 4,905 & 4,776 & 5,073 \\
\hline GDP growth (annual\%) & & & 1.8 & 11.1 & 5.9 & 9.6 & 9.4 & 12.4 & 2.0 & -3.8 & 6.3 \\
\hline Public expenditure (\% of GDP) & & & 11.6 & 10.7 & 14.6 & 17.3 & 20.3 & 22.9 & 29.1 & 30.9 & 30.7 \\
\hline Population in 1,000 & 5,438 & 5,137 & 4,435 & 4,342 & 4,315 & 4,321 & 4,401 & 4,394 & 4,382 & 4,385 & 4436.4 \\
\hline \multicolumn{12}{|l|}{ Social and Poverty } \\
\hline Subsistence minimum (average for household) & & & & & 141.5 & 160.7 & 178.7 & 198.9 & 214.6 & 216.0 & 225.3 \\
\hline \multicolumn{12}{|l|}{ Poverty } \\
\hline Share of population with less than $60 \%$ of the median consumption & & & & & 24.6 & 24.1 & 23.3 & 21.3 & 22.1 & 21.0 & \\
\hline Share of population with less than $40 \%$ of the median consumption & & & & & 10.9 & 10.1 & 9.4 & 9.2 & 9.5 & 8.8 & \\
\hline GINI coefficient & & & 38.85 & 40.37 & & 40.78 & & 36.3 & & & \\
\hline Beneficiaries of poverty assistance (\% of total population) & & & & & & & & 6.4 & 8.4 & 9.9 & 9.7 \\
\hline \multicolumn{12}{|l|}{ Health Status and Health System } \\
\hline Life expectancy at birth & 73 & 72 & 71.3 & 72.1 & 71.6 & 74.0 & 74.3 & 75.1 & 74.2 & 73.6 & 74.4 \\
\hline Infant mortality (per 1,000 live births) & 20.7 & 27.6 & 22.6 & 24.8 & 23.8 & 19.7 & 18.4 & 14.1 & 14.3 & 14.9 & 12.0 \\
\hline Hospitalizations per 100 population & 13.31 & 7.02 & 4.51 & 4.81 & 5.49 & 5.71 & 6.01 & 6.33 & 7 & 7.09 & 7.5 \\
\hline Outpatient visits per capita & 8 & 5.3 & 1.4 & 1.8 & 2 & 2.1 & 2.2 & 1.95 & 2.1 & 2 & \\
\hline \multicolumn{12}{|l|}{ Health Financing } \\
\hline Total health expenditure (THE) (\% of GDP) & & & 7.4 & 8.5 & 8.5 & 8.6 & 8.4 & 8.2 & 8.7 & 10.1 & 10.2 \\
\hline Public expenditure on health (\% of THE) & & & 16.7 & 15 & 15.4 & 19.5 & 21.6 & 18.4 & 20.7 & 23 & 23.1 \\
\hline Private expenditure on health (\% of THE) & & & & & & & 73 & 72.4 & 69.8 & 71.2 & 72.1 \\
\hline External expenditure on health (\% of THE) & & & & & & & 5.1 & 9.2 & 10.5 & 5.8 & 4.8 \\
\hline THE (year 2005 PPP\$) per capita & & & 141.7 & 232.9 & 262.1 & 302.9 & 339.1 & 384.6 & 433.0 & 499.0 & 510 \\
\hline Out-of-pocket expenditure (\% of private health expenditure) & & & 99.4 & 99.5 & 99.0 & 99.0 & 98.5 & 97.9 & 96.3 & 94.1 & 90.6 \\
\hline Prepaid health expenditure (\% of THE) & & & & & & & 22.7 & 19.9 & 23.3 & 27.2 & 29.9 \\
\hline Public expenditure on health (\% of total public expenditure) & & & 4.6 & 5.87 & 5.4 & 5.7 & 5.7 & 4.2 & 4.9 & 6.1 & 6.3 \\
\hline
\end{tabular}

Source: Geostat, National Bank of Georgia. 
group discussions, media monitoring and secondary data analysis were used to achieve a holistic understanding of the studied phenomenon. The current paper mainly focuses on the key findings obtained through the quantitative methods. Results of the policy analysis and more details on qualitative research findings will be presented in subsequent papers.

MIP impact and testing/identification of factors shaping the MIP impact were analysed using secondary data analysis of population based surveys - nationally representative Georgia Household Health Utilisation and Expenditure Surveys (HUES) 2007 [26] and 2010 [27], and the report on the Georgia MIP Impact Evaluation Survey (MIPIES) 2008 [28]. HUES 2007 and MIPIES 2008 were conducted in the initial phase of MIP implementation and provided the necessary baseline to evaluate the observed MIP impact across the criteria identified above. The impact was evaluated by comparing these baseline findings with the findings of the HUES 2010 that have generated comparable data for MIP targeted poor population, and the poor and general population not covered by MIP benefits (Table 2). Additional results of these surveys on several key outcomes, including health-related behaviours, were also considered to explain the impact of MIP on access to and utilisation of health services. The utilisation and health expenditure patterns and probability of receiving free benefits by MIP-targeted and not-targeted populations were assessed through the analysis of combined HUES 2007 and 2010 databases using the difference-in-difference (DiD) approach with logistic regression method; this method is also known as a pre-post design with a control group [29]. The change (or difference) in the outcome variable at the baseline and follow-up of MIP implementation in the treatment (or MIP covered individuals) and control group (nonMIP insured) were compared. Three sets of outcome variables were tested in the regression model: i) utilisation of services; ii) level of OOP expenditure related to service utilisation; and iii) odds of receiving free benefits without any co-payment. This method has been suggested over pre-post comparison without a control group because if a trend effect occurs during the same period as policy implementation, a simple pre-post comparison would have incorrectly attributed the trend effect to a policy impact. In a DiD framework, any trend affecting the treatment and control groups equally will be removed and the resulting net difference will be the pure policy effect. The model used can be expressed as follows:

$$
\mathrm{Y}=\beta_{0}+\beta_{1} * \mathrm{~T}+\beta_{2} * \mathrm{MIP}+\beta_{3} *(\mathrm{~T} * \mathrm{MIP})+\mathrm{e}
$$

Where, $\mathrm{Y}$ is the outcome variable of interest; $\mathrm{T}$ is a time dummy (2007-2010); MIP is a dummy for MIP insured, capturing possible differences between MIP and

Table 2 Data sources, their short description and their use for the analysis presented

\begin{tabular}{|c|c|c|}
\hline Data sources & Description & Use for the analysis presented \\
\hline $\begin{array}{l}\text { Georgia Household Health Utilisation } \\
\text { and Expenditure Surveys (HUES) in } \\
2007 \text { and } 2010\end{array}$ & $\begin{array}{l}\text { Baseline (in May-June 2007) and follow-up cross-sectional } \\
\text { surveys (June 2010) using the exact same methodology and } \\
\text { tools with nationally representative sample of households - } \\
\text { approximately 3,200 in each wave. The surveys collected } \\
\text { information for all members of the households on current } \\
\text { and past sickness episodes, including chronic diseases; } \\
\text { information on sickness and use of services and related } \\
\text { household expenditure for all cases that occurred during } \\
\text { the 30-day period prior to interview and all hospitalization } \\
\text { cases that occurred during the 12-month period preceding } \\
\text { the interview. }\end{array}$ & $\begin{array}{l}\text { The combined survey database was used to: } \\
\text { i) assess the utilisation and health expenditure } \\
\text { patterns and probability of receiving free benefits } \\
\text { by MIP targeted and not targeted population; } \\
\text { ii) to estimate catastrophic health expenditure rates. }\end{array}$ \\
\hline $\begin{array}{l}\text { Georgia Integrated Health Survey } \\
\text { (IHS) }\end{array}$ & $\begin{array}{l}\text { Nationally representative household survey conducted each } \\
\text { quarter for living standards and poverty monitoring, and } \\
\text { other statistical purposes on approx. 3,300 households in } \\
2007 \text { and approx. 6,700 households in } 2010 \text {. }\end{array}$ & $\begin{array}{l}\text { HUES } 2007 / 2010 \text { sample households were } \\
\text { included in the IHS for the respective quarter. } \\
\text { This allowed linking sickness, utilisation and } \\
\text { health expenditure data, collected in the HUES, } \\
\text { with the household consumption level, which } \\
\text { provides a proxy for income and is the basis of } \\
\text { poverty measurement in Georgia. The household } \\
\text { consumption levels established by IHS and HUES } \\
\text { 2007/2010 findings on household health } \\
\text { expenditure were used by us to estimate the } \\
\text { catastrophic health expenditure rates. }\end{array}$ \\
\hline $\begin{array}{l}\text { MIP Impact Evaluation Survey in } \\
\text { Georgia - MIPIES (World Bank, 2008) }\end{array}$ & $\begin{array}{l}\text { The survey sample of approx. 3,500 households with a } \\
\text { balance of MIP beneficiaries and non-beneficiaries was } \\
\text { drawn from the MIP applicants database for } 7 \text { regions of } \\
\text { the country accounting for } 74 \% \text { of the total population. } \\
\text { The survey conducted in November-December } 2008 \\
\text { collected information on a range of variables, including } \\
\text { utilisation of and OOP expenditure on preventive and } \\
\text { curative services. }\end{array}$ & $\begin{array}{l}\text { Survey findings on utilisation and expenditure } \\
\text { on MIP beneficiaries and non-beneficiaries were } \\
\text { compared to the HUES 2007-2010 findings. }\end{array}$ \\
\hline
\end{tabular}


non-MIP insured prior the policy change; $\beta$-0 is the baseline average; $\beta \_1$ represents the time trend in the control group; $\beta \_2$ represents the differences between the MIP and non-MIP beneficiaries in 2007; and $\beta \_3$ represents the difference in the changes by 2010 [30]. The catastrophic health expenditure rates were estimated by the researchers using the HUES 2007 and 2010 databases utilizing the methodology presented in Gotsadze et al. [31]. For comparison, alternative estimates for the same indicators were also obtained from Rukhadze and Goginashvili [32]. Their estimates are based on annual data obtained through the quarterly Georgia Integrated Household Survey (IHS) implemented by the Georgian Statistical Committee (GeoStat). Finally, two national peer reviewers using the research team network were contacted and asked to review the study findings.

The researchers use the incidence of catastrophic health expenditure to characterize the financial protection of the population, while the access to health services are measured using the indicators for health services utilisation and is analysed using a framework encompassing geographical access to health facilities, availability of medical personnel, and financial accessibility [33]. Catastrophic health expenditure is defined and estimated using methodology suggested by $\mathrm{Xu}$ et al. [34]. These specific analyses finally informed the overall analysis on the MIP impact presented in this paper.

\section{Results}

Breadth, depth and height of the achieved coverage for the general population

An overall description of the breadth, scope and depth of coverage - or who is covered, what services and to what extent services costs are covered - is presented in Table 3. There has been a striking increase in the coverage of health insurance since 2006, from less than 200,000 individuals to about 1.4 million individuals, or almost one third of the total population by the end of 2010. Out of this number, MIP accounted for over 1 million individuals, or about $23 \%$ of the total population and roughly $72 \%$ of the insured population from any source. The rest of the population is entitled to limited publicly funded health benefits, including mainly nonpersonal, population based services. This scale of expansion in the MIP coverage was achieved through an impressive $50 \%$ increase in the public expenditure on health. Since MIP inception, the public expenditure on health has grown from 40 US\$ per capita in 2006 to 61 US\$ in 2010 in constant 2009 US\$ prices [35]. MIP accounted for $43 \%$ of the total health budget in 2010, with the remaining $57 \%$ going to other health programs for the general population.

\section{Reaching the poor}

MIP has fared relatively well in reaching the poor. Table 4 shows that in the period from 2007 to 2010 the coverage of the poorest income quintile increased from $14.3 \%$ to $39.2 \%$. This means that the poorest in Georgia with the existing targeting system have received twice the share of MIP insurance benefits they would have received in a random allocation, performing on a par with the most effective targeting programs in LMIC [21], despite the fact that MIP coverage was also extended to a considerable share (13.1\%) of better-off households [27].

\section{Access to health services and financial protection of MIP targeted and general population Utilisation}

The analysis of combined HUES 2007 and 2010 databases show that the overall level of utilisation of health care, considered as contact with any type of health provider, appears to have declined slightly between 2007 and 2010, with 1.9 contacts per person per annum in 2010 compared with 2.0 in 2007 (Table 5). However, this difference is not statistically significant. At the same time, a decline in utilisation has occurred in urban areas, while there was an increase in utilisation in rural areas, from an initially lower level. Both of these changes are statistically significant. The utilisation trends differ between the individuals with acute vs. chronic illnesses. Individuals with acute sicknesses in the preceding 30 days are more likely to report using health services and report a substantial increase in utilisation from 2007, with 66\% consulting a health care provider in 2010 compared with $57 \%$ in 2007. However, the individuals with chronic illnesses utilised less services resulting in zero net effect for an overall use of services (Table 5). While there was no overall increase in the utilisation of health services for the general population, our analysis shows that the MIP beneficiaries were $2 \%$ more likely to seek any health services compared to non-beneficiaries. This difference, though very small, is statistically significant (Table 6).

In the same period, there has been no improvement in the utilisation of primary-level services. Approximately $51 \%$ of all first consultations in 2010 took place at primary level, slightly lower than in 2007 (52.7\%). Moreover, the share of MIP beneficiaries utilizing the primary health facilities for their first consultation decreased from $17.3 \%$ in 2007 to $13.1 \%$ in 2010, with shares of MIP beneficiaries utilising hospitals for the same purpose increasing at almost the same rate from $21.3 \%$ in 2007 to $25.8 \%$ in $2010(P<0.1)$ (Table 7$)$. This suggests that MIP, contrary to the stated governmental health policy objective, may have encouraged the preferential use of hospitals' outpatient services over primary health care services. 
Table 3 Breadth, scope and depth of coverage of state funded health programs and health insurance (2010)

\begin{tabular}{lll}
\hline $\begin{array}{l}\text { State vertical programs covering } \\
\text { personal health services and } \\
\text { State funded or subsidized }\end{array}$ & Population coverage & Service coverage \\
Insurance programs & & \\
\hline Urgent care (population over 60 ) & $\begin{array}{l}830,000-\text { approx. 19\% of the total } \\
\text { population }\end{array}$ & Defined inpatient urgent conditions \\
\hline $\begin{array}{l}\text { Urgent and hospital care for } \\
\text { children under } 3 \text { years of age }\end{array}$ & $220,000-5 \%$ & $\begin{array}{l}\text { Defined urgent and inpatient } \\
\text { conditions }\end{array}$ \\
\hline
\end{tabular}

Cost coverage

(covered by the state program)

First 6 days of ICU care, $75 \%$ of actual cost for predefined conditions

Full cost in case of critical conditions and population residing in high mountainous areas; $80 \%$ of actual cost for predefined inpatient conditions

General outpatient care

Little over 1 million - approx. 22\% Visits to Primary Health Care (PHC)

Fully covered/no co-payment (children under-6, elderly over 60, physician/nurse, 4 home visits, oncologic and diabetes patients) immunization, limited list of express lab tests, management of the chronic diseases

\begin{tabular}{|c|c|c|c|}
\hline $\begin{array}{l}\text { Rural outpatient care "rural } \\
\text { physician" }\end{array}$ & Little over 2 million - approx. 47\% & $\begin{array}{l}\text { Visits to PHC physician/nurse, } 4 \\
\text { home visits, immunization, limited } \\
\text { list of express lab tests, management } \\
\text { of the chronic diseases }\end{array}$ & Fully covered/no co-payment \\
\hline Maternal child health & $\begin{array}{l}\text { Women of reproductive age and } \\
\text { children }\end{array}$ & $\begin{array}{l}\text { Four prenatal visits for all. Defined } \\
\text { list of tests, extended care for high } \\
\text { risk pregnancies and complicated } \\
\text { delivery }\end{array}$ & $\begin{array}{l}\text { Upper limit from } 833 \text { to } 3,000 \text { GEL for } \\
\text { complicated pregnancy and delivery }\end{array}$ \\
\hline Emergency care (ambulance) & Entire population & $\begin{array}{l}\text { Ambulance service, medical } \\
\text { transportation }\end{array}$ & Fully covered/no co-payment \\
\hline Referral program & Entire population & $\begin{array}{l}\text { Medical needs during emergency } \\
\text { situations, MIP eligible beneficiaries } \\
\text { not yet insured; individual cases }\end{array}$ & Fully covered/no co-payment \\
\hline Cardiac surgery & Entire population & $\begin{array}{l}\text { Defined conditions; waiting list for } \\
\text { planned interventions }\end{array}$ & $\begin{array}{l}\text { Fully covered for children less than } \\
18 \text { years of age; from } 50 \text { to } 75 \% \text { of } \\
\text { the predefined price for each type } \\
\text { of surgery }\end{array}$ \\
\hline $\begin{array}{l}\text { Management of oncologic } \\
\text { diseases }\end{array}$ & Entire population & $\begin{array}{l}\text { Defined conditions; outpatient and } \\
\text { inpatient care }\end{array}$ & $\begin{array}{l}\text { Fully covered for children less than } \\
18 \text { years of age; } 70 \% \text { of the predefined } \\
\text { price of defined interventions with } \\
\text { upper limits (e.g., chemotherapy) }\end{array}$ \\
\hline Dialysis and renal transplantation & Entire population & Defined conditions & Fully covered/no co-payment \\
\hline TB control & Entire population & DOTS, outpatient and inpatient care & Fully covered/no co-payment \\
\hline Mental health & Entire population & $\begin{array}{l}\text { Defined outpatient and inpatient } \\
\text { care }\end{array}$ & Fully covered/no co-payment \\
\hline $\begin{array}{l}\text { Other programs (war veterans, } \\
\text { draftees, etc.) }\end{array}$ & Small groups & $\begin{array}{l}\text { Defined list of outpatient and } \\
\text { inpatient care }\end{array}$ & Fully covered/no co-payment \\
\hline MIP insurance & $\begin{array}{l}\text { About } 885,000 \text { poor below eligibility } \\
\text { threshold } 70,000 \text {, about } 55,000 \\
\text { between } 70,000 \text { and } 100,000 \text { scores; } \\
\text { about } 65,000 \text { other groups (teachers, } \\
\text { IDPs, orphans, etc.) - total about } \\
1 \text { million, or } 22 \% \text { of population }\end{array}$ & $\begin{array}{l}\text { Comprehensive defined list of urgent } \\
\text { care, critical care and inpatient } \\
\text { services; defined list of outpatient } \\
\text { services, outpatient drug benefit from } \\
\text { essential drug list }\end{array}$ & $\begin{array}{l}\text { Annual limits: planned inpatient } \\
\text { services - } 15,000 \mathrm{GEL} \text {; chemotherapy } \\
\text { and radiation therapy - 12,000 GEL; } \\
\text { delivery - } 400 \mathrm{GEL} \text {; outpatient drugs - } \\
50 \text { GEL, with } 50 \% \text { co-payment }\end{array}$ \\
\hline Affordable insurance* & $125,000-2 \%$ & $\begin{array}{l}\text { Urgent outpatient and inpatient care } \\
\text { and critical conditions; outpatient } \\
\text { services included in general } \\
\text { outpatient care program }\end{array}$ & $\begin{array}{l}\text { Fully covered PHC. Annual limits: } \\
\text { Urgent outpatient care - } 300 \mathrm{GEL} \text {; } \\
\text { critical care from } 1,000 \text { to } 5,000 \mathrm{GEL} \text {, } \\
\text { with co-payment from } 0-50 \%\end{array}$ \\
\hline
\end{tabular}

*2010 data.

Source: compiled by authors.

\section{Geographical access and availability of health personnel} The HUES 2007/2010 found that most of the population have access to a health facility within 30 minutes by their usual means of transport and the proportion of households that do have access has increased significantly in rural areas, reaching $78 \%$ for the population as a whole by 2010. There has also been a significant increase in the proportion of respondents (from 65 to 80\%) who report that doctors are present for at least 5 days a week at the relevant health facility (Table 8 ). 
Table 4 Coverage of the population by any health insurance and by MIP insurance, by income quintiles, 2007 and 2010

\begin{tabular}{|c|c|c|c|c|c|c|}
\hline & Year & Poorest & $2^{\text {nd }}$ & $3^{\text {rd }}$ & $4^{\text {th }}$ & Richest \\
\hline \multirow{2}{*}{$\begin{array}{l}\text { Percentage of population } \\
\text { reporting being covered } \\
\text { by any health insurance } \\
\text { (government, private or } \\
\text { employer) }\end{array}$} & 2007 & 18.5 & 14.8 & 12.5 & 14.4 & 8.6 \\
\hline & 2010 & 39.9 & 31.1 & 26.6 & 23.7 & 26.2 \\
\hline \multirow{2}{*}{$\begin{array}{l}\text { Percentage of the population } \\
\text { in households covered by MIP }\end{array}$} & 2007 & 14.3 & 13.2 & 8.3 & 9.3 & 4.2 \\
\hline & 2010 & 39.2 & 26.8 & 20.1 & 16.7 & 13.1 \\
\hline
\end{tabular}

Source: Authors and MoLHSA 2011 [27].

\section{Financial access}

According to the HUES 2007/2010, while the OOP payments for all health care services has increased (Table 9), selected financial access indicators for the general population have slightly improved over time. Namely, the proportion of individuals requiring hospitalisation but could not afford it has declined slightly, but significantly, from 3.9 to $2.6 \%$ (Table 10). Our analysis of the HUES 2007/2010 database shows less OOP expenditure for inpatient services ( -227 Gel per episode) and total monthly health care payments $(-27 \mathrm{Gel})$, and a higher probability of receiving free inpatient (by 14\%) and outpatient (by 18\%) benefits for MIP-insured (Table 6). The magnitude of a positive MIP impact on the poorest was more significant where inpatient treatment costs decreased by 442 GEL and MIP has significantly improved the probability of receiving free benefits of inpatient and outpatient services by around $23 \%$ for this group. However, MIP insurance had almost no effect on the beneficiary expenditure for outpatient drugs and for chronic patients [30].

\section{Catastrophic health expenditure}

The results on catastrophic health expenditure obtained using the HUES 2007/2010 database show a dramatic increase in the shares of the general population facing the catastrophic health expenditure from $11.7 \%$ in 2007 to $24.8 \%$ in 2010 (Table 11).

\section{Discussion}

Much of the focus of the GoG's PHC reforms in the past 7 years have been directed at increased access to primary health facilities and qualified medical personnel trained in family medicine in rural areas, thus encouraging patients to use these services [22]. However, the low overall utilisation rates of health services for the general population (two contacts per capita per year) that remained virtually unchanged in the period from 2007 through 2010, and the decline in the share of outpatient visits at PHC facilities, indicate serious failure in achieving this important health policy objective of improved access to primary health care services for the Georgian population.

The World Bank assessment of the first 6 months of MIP implementation revealed that MIP beneficiaries were nine times more likely to utilize urgent care than households that were not qualified, utilisation also increased among the poorest of the poor [36]. This impressive growth in acute care utilisation among MIP beneficiaries reported by the 2006 study is not upheld by the subsequent MIPIES 2008 and our study findings on utilisation. Our findings of moderate MIP effects on utilisation are consistent with the effects found by other studies of similar programs targeted at the poor [37].

MIPIES 2008 found that OOP payments by MIP beneficiaries were about $50 \%$ lower for outpatient services and $40 \%$ to $58 \%$ lower for inpatient services compared to what non-beneficiaries have spent. MIP beneficiaries were $17 \%$ to $26 \%$ more likely to receive free care, had lower risk of high inpatient medical care costs and were much less likely to forgo services due to financial reasons [37]. These results on MIP beneficiaries having less OOPs and higher likelihood of receiving free care are consistent with our study findings obtained through the DiD regression model.

The MIP benefit package has been steadily expanding since inception of the MIP. However, the benefit package as of November 1, 2012 still fails to cover the bulk of essential outpatient services and most importantly, a drug benefit for the chronically ill, which is one of the main cost drivers for health services and a source of

Table 5 Average numbers of consultations and utilisation of services when sick - HUES 2007/2010

\begin{tabular}{|c|c|c|c|c|}
\hline Indicator & Year & Total & Urban & Rural \\
\hline \multirow[t]{2}{*}{ Average number of consultations / contacts per person per annum (all sources of care) ${ }^{b}$} & 2007 & 2.01 & 2.36 & 1.67 \\
\hline & 2010 & 1.91 & $1.85^{* * *}$ & $1.97^{* *}$ \\
\hline \multirow[t]{2}{*}{ Average number of outpatient consultations (all types) per person per annum ${ }^{a}$} & 2007 & 1.74 & 2.03 & 1.46 \\
\hline & 2010 & 1.66 & 1.60 & 1.72 \\
\hline \multirow{2}{*}{$\begin{array}{l}\text { Percentage of total population who reported being sick with any condition in last } 6 \text { months } \\
\text { and consulted a healthcare provider }{ }^{b}\end{array}$} & 2007 & 59.5 & 59.8 & 59.3 \\
\hline & 2010 & 60.3 & 59.6 & 60.9 \\
\hline \multirow[t]{2}{*}{ Percentage of occurrences of acute illness in the past 30 days where a healthcare provider was consulted ${ }^{b}$} & 2007 & 56.5 & 55.6 & 57.9 \\
\hline & 2010 & $66.0^{* * *}$ & $68.0^{* * *}$ & $64.3^{*}$ \\
\hline
\end{tabular}

Notes: ${ }^{a}$ Significance of difference not tested; ${ }^{\mathrm{b}}$ Statistical significance of difference with baseline figure: ${ }^{* * *} P<0.01 ;{ }^{*} P<0.05 ;{ }^{*} P<0.1$.

Source: Authors and MOLHSA 2011 [27]. 
Table 6 Results of Difference-in-Difference analysis using two waves of 2007/2010 HUES data

\begin{tabular}{|c|c|c|c|c|}
\hline \multirow[t]{2}{*}{ Outcome variables } & \multicolumn{2}{|c|}{ Single difference } & \multicolumn{2}{|c|}{ Double difference } \\
\hline & Coefficient & t-statistic & Coefficient & $t$-statistic \\
\hline \multicolumn{5}{|l|}{ Service utilisation } \\
\hline Utilising any services during last 30 days & 0.02 & $2.72^{* *}$ & 0.02 & $1.95^{*}$ \\
\hline Utilising medical (curative and preventive) services during last 30 days & 0.03 & $3.99^{* * *}$ & 0.02 & $1.71^{*}$ \\
\hline Referring to self-treatment & -0.01 & -1.25 & 0 & 0.47 \\
\hline Outpatient utilization (binary) & 0.02 & $2.16^{* *}$ & 0.02 & 1.18 \\
\hline Inpatient service utilization (binary) & 0.02 & $2.80^{* * *}$ & 0.01 & 1.34 \\
\hline \multicolumn{5}{|l|}{ Household expenditure } \\
\hline Average payment per outpatient visit & -24.56 & $-4.63^{* * *}$ & -10.51 & -1.3 \\
\hline Monthly self-treatment cost & -4.84 & $-2.77^{* * *}$ & -5.3 & $-2.13^{* *}$ \\
\hline Average payment per inpatient stay & -402.94 & $-3.50^{* * *}$ & -226.93 & $-1.98^{*}$ \\
\hline Monthly chronic disease management costs & -4.84 & $-2.77^{* * *}$ & -4.98 & $-1.96^{*}$ \\
\hline Total monthly health care payments & -5.65 & $-4.31^{* * *}$ & -27.01 & $-1.94^{*}$ \\
\hline \multicolumn{5}{|l|}{ Probability of receiving free benefits } \\
\hline Outpatient free benefit & 0.28 & $9.04^{* * *}$ & 0.18 & $3.89 * * *$ \\
\hline Inpatient free benefit & 0.35 & $7.77^{* * *}$ & 0.14 & $1.77^{*}$ \\
\hline
\end{tabular}

${ }^{*} P<0.10,{ }^{* *} P<0.05,{ }^{* * * P}<0.01$.

Source: Gotsadze et al. [31].

catastrophic health expenditure in Georgia. Initial design of the MIP benefit package was mostly oriented towards inpatient services with limited outpatient coverage. After three years of full-scale implementation, the benefit package was gradually expanded covering some additional instrumental and diagnostic services and a very limited outpatient drug benefit in 2010. Nevertheless, the pharmaceutical treatment for chronic diseases remains the main trigger for increased health expenditure and a potential source of catastrophic health expenditure even for MIP beneficiaries, as pharmaceutical expenditure accounts for up to $50 \%$ of THE and up to $60 \%$ of households health expenditure [35].

Our results on catastrophic health expenditure obtained using the HUES 2007/2010 database show that the poorest quintile households were more likely to face catastrophic expenditure than other consumption quintile groups. The share of such households with catastrophic health expenditure in the poorest quintile has increased from $17.7 \%$ in 2007 to $27 \%$ in 2010 . Yet, the

Table 7 Population reporting to be sick consulting health provider and place of first consultation, HUES 2007/2010 data

\begin{tabular}{|c|c|c|c|c|c|c|}
\hline Indicator & Year & Total & Urban & Rural & MIP & Non-MIP \\
\hline \multirow[t]{2}{*}{ Percentage of total population who reported to be sick in the last 6 months } & 2007 & 53.5 & 56.2 & 51.0 & 67.3 & 51.7 \\
\hline & 2010 & $55.2^{*}$ & 56.0 & $54.5^{* *}$ & 60.6 & 53.6 \\
\hline \multirow{2}{*}{$\begin{array}{l}\text { Percentage of total population who reported to be sick in the last } 6 \text { months who } \\
\text { consulted healthcare provider }\end{array}$} & 2007 & 59.5 & 59.8 & 59.3 & 58.4 & 59.8 \\
\hline & 2010 & 60.3 & 59.6 & 60.9 & 62.2 & 59.6 \\
\hline \multirow{2}{*}{$\begin{array}{l}\text { Percentage of all first consultations, for last consultation in the last } 6 \text { months, } \\
\text { that are done at a PHC level }\end{array}$} & 2007 & 52.7 & 52.4 & 53.1 & 59.0 & 49.8 \\
\hline & 2010 & 50.9 & 50.2 & 51.5 & 55.2 & 47.0 \\
\hline \multirow{2}{*}{$\begin{array}{l}\text { Percentage of occurrences of acute sickness in last } 30 \text { days, where a health care } \\
\text { provider was consulted }\end{array}$} & 2007 & 56.5 & 55.6 & 57.9 & 56.2 & 63.3 \\
\hline & 2010 & 66.0 & 68.0 & 64.3 & 63.7 & 72.1 \\
\hline \multirow{2}{*}{$\begin{array}{l}\text { Place of first consultation at village ambulatory centre, for most recent consultation } \\
\text { in previous six months }\end{array}$} & 2007 & 9.7 & 0.3 & 19.7 & 17.3 & 8.0 \\
\hline & 2010 & 8.9 & 0.2 & 17.6 & 13.1 & 7.4 \\
\hline \multirow{2}{*}{$\begin{array}{l}\text { Place of first consultation at hospital as an outpatient, for most recent consultation } \\
\text { in previous six months }\end{array}$} & 2007 & 28.8 & 27.3 & 30.3 & 21.3 & 29.9 \\
\hline & 2010 & 29.5 & 28.5 & 30.5 & $25.8^{*}$ & 30.8 \\
\hline \multirow{2}{*}{$\begin{array}{l}\text { Person consulted is village or district doctor, for most recent consultation in previous } \\
\text { six months (all consultations) }\end{array}$} & 2007 & 17.9 & 15.1 & 20.9 & 26.1 & 16.3 \\
\hline & 2010 & 18.1 & 16.7 & 19.5 & 23.7 & 16.1 \\
\hline
\end{tabular}

Notes: Statistical significance of difference between 2010 and 2007 estimates ${ }^{* *} P<0.05 ;{ }^{*} P<0.1$. Source: Authors and MoLHSA 2011 [27]. 
Table 8 Physical access and availability of services - HUES 2007/2010

\begin{tabular}{|c|c|c|c|c|}
\hline Indicator & Year & Total & Urban & Rural \\
\hline \multirow{2}{*}{$\begin{array}{l}\text { Percentage of total population with access within } 15 \text { minutes by normal means of travel to a facility where they } \\
\text { would normally see a doctor }\end{array}$} & 2007 & 42.4 & 55.6 & 31.4 \\
\hline & 2010 & $49.7^{* * *}$ & $62.6^{* *}$ & $37.6^{* *}$ \\
\hline \multirow{2}{*}{$\begin{array}{l}\text { Percentage of total population with access within } 30 \text { minutes by normal means of travel to a facility where they } \\
\text { would normally see a doctor }\end{array}$} & 2007 & 81.9 & 93.5 & 72.5 \\
\hline & 2010 & $85.5^{* *}$ & 93.6 & $77.8^{*}$ \\
\hline \multirow[t]{2}{*}{ Percent of health facilities (other than ambulatory) where a doctor is reported to be present for 5 or more days a week. } & 2007 & 98.1 & 99.3 & 95.9 \\
\hline & 2010 & $99.0^{*}$ & 99.4 & 98.0 \\
\hline
\end{tabular}

Notes: Statistical significance of difference with baseline figure: ${ }^{* *} P<0.01 ;{ }^{* *} P<0.05 ;{ }^{*} P<0.1$.

Source: Authors and MoLHSA 2011 [27].

gradient between the poorest and richest households in the same period declined by more than $20 \%$ (Table 11 ). The analysis conducted by Rukhadze and Goginashvili using the results of the Georgia Household Budget Survey (HBS) show a similar trend. The actual values for catastrophic expenditure for health derived from the HUES are much higher than those reported by Rukhadze and Goginashvili using the HBS data. This may be explained by a significantly higher level of health expenditure captured by HUES compared to HBS [31].

There is a seeming contradiction between improved geographical access and financial access for both MIP beneficiaries and the general population on the one side and almost unchanged overall utilisation patterns, increased OOP expenditure and worsened financial protection indicators for the total population on the other that requires explanation. There are at least three possible causes for the observed effect.

Firstly, double negative impact of the war with Russia and the global economic recession on the Georgian economy and population welfare has significantly reduced households' total consumption from 408.6 GEL in 2008 to 364.6 GEL in constant 2006 prices [32], while increase in total and private health expenditure has outpaced the inflation rate and GDP growth: total health expenditure (THE) increased from $8.7 \%$ of GDP in 2008 to $10.2 \%$ of GDP in 2010 , with private expenditure increasing from $69.8 \%$ to $72.1 \%$ of THE in the same period (Table 1). This adversely affected the financial protection for the entire population: OOP expenditure increased for all types of services (Table 9) and catastrophic health expenditure increased for all population groups, including the MIP beneficiaries (Table 11). However, the increase in OOP health expenditure, particularly for inpatient services, disproportionally affected the non-MIP population, while benefiting the MIP population (Table 9).

Secondly, the increase in private expenditure was most notable for pharmaceuticals consumed on a daily basis by $40 \%$ of the Georgian vulnerable households [38] and mostly not covered by MIP. This expenditure amounted to $50 \%$ of THE [35] and $60 \%$ of total household expenditure on health in 2010, which, in turn has increased by $21 \%$ in real terms in the period from 2007 through 2010 [27]. This dramatic increase in pharmaceutical expenditure may be related to irrational prescription practices and the largely unregulated pharmaceutical market in Georgia [22,39].

Thirdly, there is compelling evidence that despite the extended breadth, depth and scope of coverage provided, MIP was unable to shield the vast majority of the population from catastrophic health expenditure. In the period from 2008 through 2010, only 13.8\% of MIP beneficiaries used the insurance. In the same period, the claims ratio, or the amount paid in claims against the total premium amounted to the average of only $65 \%$ and in $45 \%$ of insurance cases reimbursed health expenditure did not exceed 20 GEL (less than 5\% of total household consumption) [40]. Yet, this relatively low claims ratio, though not

Table 9 Household health care expenditure (GEL, current prices) - HUES 2007/2010

\begin{tabular}{|c|c|c|c|c|c|c|}
\hline & \multicolumn{3}{|l|}{2007} & \multicolumn{3}{|l|}{2010} \\
\hline & Non-MIP & MIP & Total & Non-MIP & MIP & Total \\
\hline Mean fee paid to a provider per outpatient visit & 40.1 & 19.2 & 36.6 & $59.5^{* *}$ & 21.8 & $54.2^{* *}$ \\
\hline Mean cost per prescribed drug purchased & 26.8 & 21.3 & 25.9 & $36.5^{* * *}$ & $28.6^{* *}$ & $35.4^{* * *}$ \\
\hline Mean expenditure per case of self-treatment & 13.5 & 12.9 & 13.4 & $20.6^{* * *}$ & $19.0^{* *}$ & $20.4^{* * *}$ \\
\hline Annualized expenditure per chronic patient & 276.2 & 227.1 & 267.1 & $426.0^{* * *}$ & $307.2^{* * *}$ & $411.1^{* * *}$ \\
\hline Average cost per inpatient stay & 636.8 & 414.4 & 599.2 & $730.7^{*}$ & 364.9 & 684.4 \\
\hline Total annualized per capita expenditure & 190.8 & 198.0 & 192.1 & $313.3^{* *}$ & $278.4^{* *}$ & $307.2^{* *}$ \\
\hline
\end{tabular}

Notes: Statistical significance of difference with baseline figure: ${ }^{* *} P<0.01 ;{ }^{*} P<0.05 ;{ }^{*} P<0.1$.

Source: Authors and MoLHSA 2011 [27]. 


\begin{tabular}{|c|c|c|c|c|}
\hline Indicator & Year & Total & MIP & Non-MIP \\
\hline \multirow{2}{*}{$\begin{array}{l}\text { Percentage of occurrences of acute sickness in the last } 30 \text { days, where no consultation was undertaken because } \\
\text { it was too expensive/not enough money (\% of all reasons) }\end{array}$} & 2007 & 16.1 & 15.3 & 16.2 \\
\hline & 2010 & 16.7 & 17.8 & 13.9 \\
\hline \multirow{2}{*}{$\begin{array}{l}\text { Percentage of consultations where medicine was prescribed but not purchased because it was too expensive } \\
\text { (base: all consultations in previous six months) }\end{array}$} & 2007 & 11.8 & 19.4 & 10.3 \\
\hline & 2010 & 13.1 & 21.4 & 10.2 \\
\hline \multirow{2}{*}{$\begin{array}{l}\text { Percentage of consultations where a lab test was prescribed but not done because it was too expensive } \\
\text { (base: all consultations in previous six months) }\end{array}$} & 2007 & 4.2 & 6.9 & 3.7 \\
\hline & 2010 & 4.2 & 5.0 & 4.0 \\
\hline \multirow{2}{*}{$\begin{array}{l}\text { Percentage of total population who reported needing hospitalisation in the last year but were not hospitalised } \\
\text { because it was too expensive/they did not have enough money }\end{array}$} & 2007 & 3.9 & - & - \\
\hline & 2010 & $2.6^{* * *}$ & 2.3 & 2.7 \\
\hline \multirow[t]{2}{*}{ Percentage of respondents who expect to pay for a consultation with a doctor at the nearest facility } & 2007 & 72.6 & 57.0 & 75.7 \\
\hline & 2010 & 73.5 & $51.5^{*}$ & $80.9^{* *}$ \\
\hline
\end{tabular}

Notes: ${ }^{* *} P<0.01$; ${ }^{* *} P<0.05 ;{ }^{*} P<0.1$.

Source: Authors and MoLHSA 201 [27].

unusual [41], may have been caused by delays - possibly intentional - in enrolment of the eligible beneficiaries and aggressive utilisation management by some of the participating PICs and poorly informed beneficiaries [40]. Following this logic, curtailment of these adverse practices and the increased beneficiary awareness may have contributed to a significant increase in the claims ratio in subsequent years, reaching $98 \%$ in 2012 [42].

Considering all the above, we suggest that the extended MIP coverage and increased financial access provided by the program, were most likely not able to reverse the adverse effects of economic slow-down and escalating health expenditure and have only cushioned the negative impact for the poorest by decreasing the poor/rich gradient in the rates of catastrophic health expenditure. Flaws in the MIP benefit package and possible adverse practices employed by the PICs may have played critical role in diminishing the desired impact of MIP at the initial implementation stage presented here.

Addressing problems in equity and financial protection against health care costs through re-attainment of

Table 11 Estimates of shares of households with catastrophic health expenditure in 2007 and 2010 (\%)

\begin{tabular}{llllll}
\hline & $\mathbf{2 0 0 7}$ & & & $\mathbf{2 0 1 0}$ & \\
\cline { 2 - 3 } \cline { 5 - 6 } & HUES & HBS & & HUES & HBS \\
\hline Poorest & 17.7 & 11.6 & & 27.0 & 13.3 \\
$\mathbf{2}^{\text {nd }}$ quintile & 12.0 & 6.3 & 27.9 & 9.8 \\
$\mathbf{3}^{\text {rd }}$ quintile & 10.1 & 4.5 & 24.2 & 7.2 \\
$\mathbf{4}^{\text {th }}$ quintile & 8.4 & 3.8 & 24.5 & 5.8 \\
Richest & 10.3 & 3.7 & 20.6 & 6.4 \\
MIP & & & 22.4 & \\
Non-MIP & & & 35.2 & \\
Total & $\mathbf{1 1 . 7}$ & $\mathbf{6 . 0}$ & $\mathbf{2 4 . 8}$ & $\mathbf{8 . 5}$ \\
\hline
\end{tabular}

Source: Authors estimates for HUES 2007/2010; Rukhadze and Goginashvili for HBS [32]. universal coverage for essential health care services for the entire population is one of the longstanding and explicitly stated national health policy goals in Georgia [43]. However, the first practical steps towards achievement of this goal were made only in recent years, when more funds became available to the health sector. Paradoxically, this happened in the situation when the overarching goal of achievement of universal coverage for the entire population was removed from the formal public agenda in favour of the "selective" approach targeting the priority groups [44]. The idea of providing universal coverage to the entire population has re-emerged on the policy agenda with the victory of the new political party in Georgia in the fall of 2012. It is unclear whether the existing PPP's in providing health insurance coverage will continue to exist and or which dimension of the coverage (breadth, depth, or height) will be favoured as a strategy towards achievement of this goal. The research team believes that findings and results of the current study may also help to inform policy makers to determine the future path of the planned health financing reform.

\section{The study limitations}

In comparison to previous impact evaluation studies and in consideration of policy implications of the findings, it is important to keep the limitations of the study in mind. First, given limitations of the data we have not considered the impact of the MIP on health outcomes. Second, the inflation adjusted prices considered the conservative approach by applying the overall Consumer Price Index of Georgia and not the health-specific inflation rate (i.e., on average of $25 \%$ in year 2010). Thirdly, the consumption groups assessed do not account for those receiving government subsidies, hence there may be those belonging in the "poor" quintile that may have consumed more and hence be reported as higher quintile due to the subsidy negatively distorting results characterizing the 
effectiveness in MIP targeting. Finally, it is worth noting that since the research focused only on the first three years of MIP implementation, it may have been too early to assess its long-term effects. Further research is needed to address these issues.

\section{Conclusions}

MIP has contributed to an improvement in all three dimensions - population, service and cost coverage, and managed to improve financial protection of the beneficiaries that used health services against expenditure related to inpatient care. This, in turn, had a positive impact on financial access indicators for the poorest in the general population, but had limited or no overall effect on utilisation of health services and financial protection for the general population as measured by the incidence of catastrophic health expenditure. The study results also suggest that the sustained low utilisation of health services, particularly primary health care services for the general population including MIP beneficiaries is mainly determined by the limited financial accessibility of outpatient pharmaceuticals. As a result, exclusion of an outpatient drug benefit from MIP benefit package during the first three years of implementation has detrimentally affected the potential impact of MIP on financial protection of the population. There are also indications that improper practices employed by the PICs - delayed enrolment and overly aggressive utilisation management may have also contributed to the low utilisation at the initial stage of MIP implementation. Alternative approaches to protecting households experiencing catastrophic health expenditure might need to be explored, most important of which may be the expansion of the MIP benefit package to cover a reasonable outpatient drug benefit that will include coverage of the leading causes of chronic illnesses such as hypertension and other cardiovascular diseases, bronchial asthma, gastroenterology disorders, etc. Policies for the rationalization of unreasonably high pharmaceutical expenditure should also be pursued.

The recent governmental decision on major expansion of MIP coverage and inclusion of additional drug benefits are expected to significantly enhance the overall MIP impact and its potential as a viable policy instrument for achieving universal coverage. However, it appears that there is no clear consensus yet among policy makers in which direction to proceed in for the further improvement of the population's financial protection, which presents a window of opportunity for the researchers and advocacy groups to provide sound evidence and influence the decision-making process.

\section{Abbreviations}

DiD: Difference in difference; GDP: Gross domestic product; GEL: Georgian Lari; GeoStat: Georgian Statistical Committee; HBS: Household budget survey; HUES: Health expenditure and utilisation survey; LMIC: Low- and middleincome countries; MIPIES: Georgia MIP impact evaluation survey;
MIP: Medical insurance for poor; OOP: Out-of-pocket expenditure; PICS: Private insurance companies; SBASS: Survey of barriers to access to social services in Georgia.

\section{Competing interests}

The authors declare that they have no competing interests.

\section{Authors' contributions}

AZ led the research design and implementation as a principal investigator, conducted literature and document review, together with NR performed overall analysis of the quantitative data and finally, drafted the manuscript. NR, KC (who also provided overall coordination of the research) and GG worked on the secondary data analysis. GG also reviewed the draft manuscript. All authors have read and approved the final manuscript.

\section{Acknowledgements}

We acknowledge that this study is financially and technically supported by the Alliance for Health Policy and Systems Research, WHO. We also wish to acknowledge the inputs of the Health Systems Financing Department, WHO and the late Guy Carrin, in particular. Our special appreciation goes to Di McIntyre for her guidance during the preparation of the study proposal and the manuscript review. We also appreciate contributions from Kent Ranson, Ayako Honda and Lucy Gilson to the research design process. The researchers express their gratitude to Bhupinder Kaur Aulakh for continuous support during the study implementation.

Received: 7 December 2012 Accepted: 30 October 2013 Published: 15 November 2013

\section{References}

1. Leemput L, Ponsar F, Philips M, Bricki N: Health equity funds in Cambodia. Lancet 2007, 369(9562):638.

2. Meessen B, Pei X, Criel B, Bloom G: Health and Social Protection: Experiences from Cambodia. China and Lao PDR, Antwerp: ITG press; 2008.

3. Sparrow R, Suryahadi A, Widyanti W: Social health insurance for the poor: targeting and impact of Indonesia's Askeskin programme. Soc Sci Med November 2013, 96:264-271.

4. Preker A, Carrin G, Dror D, Jakab M, Hsiao W, Arhin-Tenkorang D: Rich-poor differences in health care financing. In Health Financing for Poor PeopleResource Mobilization and Risk Sharing. Washington DC: World Bank; 2004:3-52.

5. Jowett M, Hsiao W: Philippines: extending coverage beyond the formal sector. In Social Health Insurance for Developing Nations. Washington DC: World Bank; 2007:81-104.

6. Arfa C, Achouri $\mathrm{H}$ : Tunisia: good practices in expanding health care coverage. Lessons from reforms in a country in transition. In Lessons from Reforms in Low- and Middle-Income Countries. Good Practices in Health Financing. Edited by . Washington DC: World Bank; 2008:385-437.

7. Wagstaff A, Policy Research Working Paper, No WPS 4134: Health Insurance for the Poor: Initial Impacts of Vietnam's Health Care Fund for the Poor. Washington, DC: World Bank; 2007.

8. Mkandawire T: Targeting and Universalism in Poverty Reduction. Social Policy and Development Programme PaperNo 23. Geneva: UNRISD; 2005. http:// www.unrisd.org/80256B3C005BCCF9/(httpPublications)/ 955FB8A594EEA0B0C12570FF00493EAA.

9. Meng Q, Yuan B, Jia L, Wang J, Yu B, Gao J, Garner P: Expanding health insurance coverage in vulnerable groups: a systematic review of options. Health Policy Plann 2011, 26(2):93-104.

10. Drechsler D, Jutting J: Policy Insights, No. 11: Private Health Insurance for the Poor in Developing Countries. Paris: OECD Development Centre; 2005.

11. Miller G, Pinto D, Vera-Hernandez M: High-powered Incentives in Developing Country Health Insurance: Evidence from Colombia's Régimen Subsidiado. National Bureau of Economic Research Working Paper No.15456. Cambridge, MA: NBER; 2009.

12. Basu R: Rashtriya Swasthya Bima Yojana: Pioneering Public-Private Partnership in Health Insurance. New Delhi: Jamia Millia Islamia; 2010. http://www. napsipag.org/PDF/RUMKI\%20BASU.pdf.

13. Drechsler $D$, Jütting J: Private health insurance in low- and middle-income countries - scope, limitations, and policy responses. In 2005 Wharton Impact Conference, 15-16 March, 2005. Wharton; 2005.

14. Sekhri N, Savedoff W: Private health insurance - implications for developing countries. Bull WHO 2005, 83(2):127-138. 
15. WHO: The World Health Report: Health Systems Financing: The Path to Universal Coverage. Geneva: World Health Organization; 2010.

16. Gilson L, Doherty J, Loewenson R, Francis V: Challenging Inequity through Health Systems. Final Report. Knowledge Network on Health Systems. Geneva: WHO Commission on the Social Determinants of Health; 2007.

17. Patouillard E, Goodman C, Hanson K, Mills A: Can working with the private for-profit sector improve utilisation of quality health services by the poor? A systematic review of the literature. Int J Equity Health 2007, 6:17.

18. Gilson L, Raphaely N: The terrain of health policy analysis in low and middle income countries: a review of published literature 1994-2007. Health Policy Plann 2008, 23(5):294-307.

19. Hou X, Chao S: Evaluation of the Initial Impact of the Medical Assistance Program for the Poor in Georgia, World Bank Policy Research Working Paper Series, 1. Washington DC: World Bank; 2008.

20. The World Bank: Georgia Poverty Assessment. Washington DC: World Bank; 2009.

21. Grosh M, Ninno C, Tesliuc E, Ouerghi A: For Protection and Promotion: The Design and Implementation of Effective Safety Nets. Washington DC: World Bank; 2008.

22. Chanturidze T, Ugulava T, Durán A, Ensor T, Richardson E: Georgia: health system review. Health Systems in Transition 2009, 11(8):1-116.

23. Djadugishvili S: Health Financing in Georgia 1990-2010. Insurance Association of Georgia: Tbilisi; 2010.

24. Ministry of Finance of Georgia: Information on anticipated outcomes and indicators for the programs defined by the State Budget of Georgia 2012. [http://www.mof.ge/common/get_doc.aspx?doc_id=8726] Accessed 23 January 2012

25. Gotsadze G, Gaal P: Coverage decisions: benefit entitlements and patient cost sharing. In Implementing Health Financing Reform: Lessons from Countries in Transition. Edited by Kutzin J, Cashin C, Jakab M. Copenhagen: WHO on behalf of the European Observatory for Health Systems; 2010:187-217.

26. MoLHSA, Department of Statistics, Ministry of Economic Development, Oxford Policy Management, UK, Curatio International Foundation: Results from a Household Survey on the Use of Health Services and Expenditure on Health. Final Report. Tbilisi: Georgia Primary Health Care Development Project; 2007.

27. MoLHSA, Department of Statistics-Geostat, Oxford Policy Management, UK, Curatio International Foundation: Results from Two Rounds of a Household Survey on the Use of Health Services and Expenditure on Health. Final Report. Tbilisi: Georgia Primary Health Care Development Project; 2011.

28. MoLHSA: Georgia MAP Impact Evaluation Survey 2008. Tbilisi: Georgia Primary Health Care Development Project; 2008.

29. Abadie A: Semiparametric difference-in-difference estimators. Rev Econ Studies 2005, 72:1-19.

30. Gotsadze G, Zoidze A, Rukhadze N: Purchasing Private Health Insurance for Poor in Georgia: Preliminary Results and Policy Implications. Proceedings of the International Health Economics Association: Sydney; 2013

31. Gotsadze G, Zoidze A, Rukhadze N: Household catastrophic health expenditure: evidence from Georgia and its policy implication. Bmc Health Serv Res 2009, 9:69

32. Rukhadze N, Goginashvili K: Distribution of Health Payments and Catastrophic Expenditures in Georgia: Analysis for 2006-2010 (Annual Level Data). MoLHSA: Tbilisi; 2011.

33. Peters DH, Garg A, Bloom G, Walker D, Brieger W, Rahman H: Poverty and access to health care in developing countries. Ann N Y Acad Sci 2008, 1136:161-171.

34. Xu K, Evans D, Kawabata K, Zeramdini R, Klavus J, Murray C: Household catastrophic health expenditure: a multi-country analysis. Lancet 2003, 362:111.

35. WHO: WHO Global Health Expenditure Database. 2013. [http://apps.who.int/ nha/database/standardreport.aspx?id=rep_web_mini_template_web_ version\&countrykey=84638] Accessed 2 June 2013.

36. Hou $X$, Chao S: Targeted or untargeted? The initial assessment of a targeted health insurance program for the poor in Georgia. Health Policy 2011, 102(2):278-285.

37. Bauhoff S, Hotchkiss D, Smith O: The impact of medical insurance for the poor in Georgia: a regression discontinuity approach. Health Econ 2011, 20(11):1326-1378.

38. UNICEF, USAID HSSP: Survey of Barriers to Access to Social Services in Georgia in 2010: Why Don't all Poor Families get Social Benefits and Services? Survey
Report. 2011. [www.unicef.org/georgia/BASS_final-eng.pdf] Accessed 25 December 2011.

39. Gotsadze T: Rationalizing Pharmaceutical Expenditures in Georgia. Position Paper. 2011, [http://www.psidiscourse.ge/files/files/pdfs/ Rationalization\%20of\%20the\%20Pharmaceutical\%20Expenditures\%20in\% 20Georgia.pdf] Accessed 4 June 2013.

40. Chamber of Control of Georgia: Audit for the State-Run Health Insurance Program. 2011. [Available: http://sao.ge/news/273] Accessed 25 December 2011.

41. Selvavinayagam T, Vijayakumar S: Overview of publicly funded health insurance: Tamil Nadu model. Indian J Community Med 2012, 37(3):194-196.

42. Georgia Insurance Association: Georgia Insurance Association. 2013, [http://www.insurance.org.ge/index.php?a=main\&pid=215\&lang=eng] Accessed 2 October 2013.

43. MoLHSA: Strategic Health Plan for Georgia 2000-2009. Tbilisi: Ministry of Labour, Health and Social Affairs of Georgia; 1999.

44. OSGF: Independent Georgia: social protection and health care systems. Analytical Review. 2012, [http://www.osgf.ge/files/publications/ Analytical_Review_Final_Edited_March_2012.pdf] Accessed 5 March 2012.

doi:10.1186/1478-4505-11-45

Cite this article as: Zoidze et al:: Promoting universal financial protection: health insurance for the poor in Georgia - a case study. Health Research Policy and Systems 11:45.

\section{Submit your next manuscript to BioMed Central and take full advantage of:}

- Convenient online submission

- Thorough peer review

- No space constraints or color figure charges

- Immediate publication on acceptance

- Inclusion in PubMed, CAS, Scopus and Google Scholar

- Research which is freely available for redistribution

Submit your manuscript at www.biomedcentral.com/submit
C) Biomed Central 